\title{
Production of Reactive Oxygen Species, Unbalanced by Endogenous Antioxidant Capture Mechanisms Monitored in Surgically Treated Breast Cancer
}

\author{
ALINA OANA RUSU-MOLDOVAN ${ }^{1,4}$, MARIA IULIANA GRUIA ${ }^{2 *}$, \\ CAMELIA-MANUELA MIRZA ${ }^{3}$, DAN MIHU ${ }^{4}$ \\ ${ }^{1}$ Institute of Oncology Bucharest, Department of Surgery III, 252 Fundeni Road, Bucharest Romania \\ ${ }^{2}$ Institute of Oncology Bucharest, Department of Biochemistry and Radiobiology, 252 Fundeni Road, Bucharest Romania \\ ${ }^{3}$ Iuliu Hatieganu University of Medicine and Pharmacy, Discipline of Pathophysiology, 8 Victor Babes Str., Cluj-Napoca, \\ Romania \\ ${ }^{4}$ Iuliu Hatieganu University of Medicine and Pharmacy, Second Clinic of Obstetrics and Gynecology, 8 Victor Babes Str., \\ Cluj-Napoca, Romania
}

\begin{abstract}
Oxidative stress is defined as an imbalance between the production of oxygen reactive species (ROS) and their endogenous capacity of capturing them. Oxidative stress activates multiple effects generated by the non-specific growth of the ROS and by the decrease of antioxidant concentrations and neutralization mechanisms. The most accurate understanding of the mechanisms underlying oxidative stress and the deepening of its implications in different cancers has become very important in recent decades. Cancer cells are usually subjected to high levels of ROS, which continually activates the malignant phenotype by stimulating cell proliferation - by increasing the mitotic rate, angiogenesis, invasiveness and metastasis rates. The role of the ROS in the etiology and progression of breast cancer is in continuous processing. However, less attention has been paid to the development of redox-targeted breast cancer therapy strategies. Excess ROS production is detrimental for the survival and proliferation of neoplastic cells, through the oxidative-destructive mechanisms of biomolecules essential for life. This study departs from the hypothesis that the tumor is an inductive factor of oxidative stress, and an antioxidant treatment prior to surgery may influence the response to surgical treatment in breast cancer patients. This response is highlighted by determining certain essential compounds of the redox balance, after initiating the antioxidant therapy. Moreover, we have tried to assess the possible biochemical changes given by age, tumor size and asymmetry/laterality of the neoplasm in the investigated patients, and to determine the prognostic or predictive factors of these changes.
\end{abstract}

Keywords: oxidative stress, antioxidants, breast cancer, laterality

\section{Introduction}

Oxidative stress is defined as an imbalance between the production of reactive oxygen species (ROS) and their endogenous capacity to capture them [1]. To prevent cell damage from oxidative stress, aerobic body cells have developed a number of extremely powerful anti-oxidant strategies. However, oxygen-reactive species may be generated accidentally as a consequence of the deterioration of cell metabolism (e.g. during cell respiration) or may be formed in inflammation. Thus, it is explained why some metabolic disorders, as well as conditions associated with an inflammation threshold, express an increased amount of oxidative stress biomarkers [2, 3].

During intra-cellular metabolism oxygen can be activated (by electron gain, or by power gain) with the formation of highly reactive chemical species. The cell is therefore continuously exposed to cytotoxic action of reactive oxygen species, a potential hazard to cell integrity. 
The mitochondrial respiratory chain is the main source of the oxidative stress in cells, and thus the oxidative species produced by the malignant cells have various effects with a wavy character [4]. In neoplastic cells an increase in reactive oxygen (ROS) species is identified, resulting as oncogenic stimulation, an increase in metabolic activity, even in mitochondrial damage.

In the case of increased oxidative stress, free radicals can cause cytotoxicity, inhibit cell proliferation and induce cell death through apoptosis or necrosis. Medium and /or low oxidative stress can induce cell mutations, by actively participating in the carcinogenesis process [5]. It is well known as in high concentrations, that reactive oxygen species (ROS) have a destructive action on the cellular level, but in low concentrations they can act as signal molecules.

Inflammation, infection, extreme physical effort, exposure to harmful environmental factors may cause an increase in the production of free radicals in the body [6,7]. Studies in this regard have shown that antioxidants may induce the apoptosis of malignant cells, sparing normal cells and inhibiting cell proliferation $[7,11]$.

It has been proven in various studies that neutralization or capture of free radicals prevents cellular destruction due to chemical reactions between oxidative and protein species and/or nucleic acids $[8,9$, $10]$.

The excessive production of free radicals and/or the lack of antioxidants so necessary for the immune system may trigger oxidative stress by damaging DNA and other molecules [8, 9]. The primary effect is localized and reversible, compensated or prolonged depending on the intensity of oxidative stress and on the level of antioxidants. The transition to the secondary effect marks the irreversible phase. If minor symptoms occur in the primary stage, the transition to the secondary effect is joined by the clinical manifestations caused by cell lyse, altered functions, low resistance to effort, or infections. The condition of associated illness becomes obvious. These impairments become irreversible and may trigger neoplasia. Therefore, it is known that oxidative stress and lipid peroxidation play an important role in the etiology of breast cancer [9, 12].

Antioxidants are compounds that have the ability to reduce ROS, and they are classified into endogenous and exogenous, enzymatic, non-enzymatic antioxidants. Among the primary, important endogenous antioxidants, we may mention the enzymatic ones: superoxide dismutase, catalase and glutathione peroxidase, or non-enzymatic - vitamin E, C; while the exogenous ones are chemical compounds with polyphenolic structure, anthocyanin, propaphenols, and so one [13].

An important role has been given to exogenously administered antioxidants, such as vitamin A, E, $\mathrm{C}$, selenium and the precursors of vitamin A: beta-carotene, lecithin, lutein $[6,7]$.

These compounds are known as the "carriers" of free radicals, because they reduce oxidative stress and the oxidative destruction of DNA $[8,10,14]$.

Many oxidizing agents are first generated in the aqueous phase, water-soluble antioxidants must be considered first-line antioxidants. Aqueous phase antioxidants probably act as primary carriers. They react directly with toxic oxygen metabolites to form more stable compounds [15]. On the other hand, lipid antioxidants are more effective. They are protective against lipid peroxidation. The grade of protection against the molecule depends on the depth of the lipophilic part of that molecule, through which it is anchored to the lipid membrane, causing a synergistic cooperation of bio-antioxidants at cellular level [16].

This study starts from the hypothesis that the tumor is an inductive factor of oxidative stress. Moreover, we attempted to show the possible changes in oxidative stress metabolite levels corelated to age, tumor size and laterality of the cancer in the investigated patients. As a result of the study we wish to highlight the need for antioxidant treatment, which can favorably influence oxidative stress metabolism and the response at surgical stress. 


\section{Material and method}

There were studied in dynamic 93 patients with breast cancer, admitted in the Surgery Department III of the Oncology Institute of Bucharest for surgery treatment, between October 2016 and December 2018.

The patients were diagnosed with breast cancer, the results firmly confirmed by histopathological reports, showing that the tumors were ductal carcinomas with its subtypes cribriform and tubular carcinoma with invasion in the peritumoral fatty tissue, non-encapsulated, and hard consistency. The 93 patients as histopathology tumor type were distributed as follows: 56\% pure invasive ductal carcinomas, $16 \%$ cribriform carcinomas, $12 \%$ tubular carcinomas and $16 \%$ cribriform and tubular carcinomas. Immunohistochemically were divided into: 47 patients $(50,55 \%)$ Luminal A, 28 patients $(30,10 \%)$ Luminal B, 14 patients $(15,05 \%)$ Triple negative and 4 patients $(4,30 \%)$ HER enriched.

In the Luminal A group 11 patients presented G1 tumors,32 patients G2 tumors and 4 patients G3 tumors and Ki67 between 0-10\%. The Luminal B group presented: 4 patients with G1 tumors, 11 patients G2 tumors and 13 with G3 tumors and Ki67 between (10-45\%). The triple negative group presents: 2 patients with G1 tumors and Ki67 $=35 \%, 5$ patients with $\mathrm{G} 2$ tumors and Ki67 $=45-55 \%$ and 7 patients with G3 tumors and Ki67=70-80\%. And the last group presents 2 patients with G2 tumors and $\mathrm{Ki} 67=15 \%$ and 2 with G3 tumors and Ki67=35\%.

The approval of the study was obtained from the Ethics Committee of the Oncology Institute of Bucharest.

After giving their personal consent in writing, whole blood samples were collected by venous puncture. By centrifugation, the blood serum was isolated, and then the following determinations were made:

- The lipid peroxides were evaluated by measuring the final concentration of malondialdehyde (MDA). The method is spectrophotometric and is based on the formation of a colored adduct (MDA$\mathrm{TBA}_{2}$ ) that develops maximum absorption at $532 \mathrm{~nm}$ depending on the concentration.

- The oxidative activity of ceruloplasmin may be measured by several methods. Blue protein with oxidative activity on polyamines, polyphenols and inorganic ferrous ions $\left(\mathrm{Fe}^{2+}\right)$ has high affinity for them. We used the Ravin method by reaction with p-phenylenediamine in acetic acid-acetate pad. The color intensity developed at $540 \mathrm{~nm}$ is directly proportional with the concentration of the measured compound.

- The thiol-albumin groups TA were determined by reaction with the 5,5-dithiobis (2nitrobenzoic) acid, Ellman's reagent, which, following oxidations, develops the maximum intensity at $412 \mathrm{~nm}$ in accordance with the concentration of the SH groups formed.

- The total antioxidants were biochemically measured by a method that utilizes the ability of the serum to reduce iron. When the $\mathrm{pH}$ is low, the $\mathrm{Fe}^{\mathrm{III}}$-tripyridyl-s-triazine complex (Fe ${ }^{\mathrm{III}}-\mathrm{TPTZ}$ ) is reduced to its ferrous form, by forming a new complex that develops an intense blue color, measurable, with a maximum absorption at $593 \mathrm{~nm}$. Any reaction with a positive redox potential in the aforementioned conditions may cause the reduction of the Fe ${ }^{\mathrm{III}}$-TPTZ complex. Using an excess of Fe, the limiting factor of the Fe $\mathrm{FII}_{\text {IIPTZ }}$ complex and of color formation represents the reducing ability of the sample.

In order to make these determinations, the solutions were prepared using compounds of analytical purity from Merck and Sigma, dedicated to clinical studies, the water that has been used was genetically pure after filtering by Millipore devices (Milli-Q-Biocel), and the spectrophotometric readings were carried out on a Specord 210 spectrophotometer (AnalyticJena).

\section{Statistical analysis}

Elements of descriptive statistics were calculated, the data being presented using centrality, localization and distribution indicators.

For the normal distribution test, the Shapiro-Wilk test was used, and variation was tested by F test. 
As regards data with normal distribution, the t test (Student) was used, and as regards values with uneven distribution or ranks, the nonparametric Mann-Whitney (U) test was used. The significance threshold for the used tests was $\alpha=0.05$ (5\%), 0.01 (1\%) or 0.001 .

The Pearson correlation coefficient ( $r$ ) was used to identify the correlation between two continuous quantitative variables with normal (even) distribution. For variables with uneven distribution, the correlation coefficient of Spearman ranks $(\rho)$ was used. The analysis of the correlation coefficients was made using Colton's rule.

The StatsDirect v.2.7.2 program was used for statistical data processing. The graphical representation of the results was made by Excel application (from the Microsoft Office 2010 package).

\section{Results an discussions}

The clinical condition of the patients was evaluated by complete clinical examination, and the performance status was evaluated using the ECOG scale. When setting the diagnosis, $77.4 \%$ of the patients (72/93) had a good performance status - ECOG 0 (fully active; able to complete the activities that they had carried before getting sick), 19.4\% (18/93) with ECOG 1 (restrictions in carrying out demanding physical activities, but mobile, able to carry out normal light activities or physically undemanding sedentary activities, and 3.2\% (3/93) with ECOG 2 (mobile, apparently active, capable to take care of themselves, but unable to work for more than $50 \%$ of the physically active time).

In the studied group, in terms of distribution from an anatomical-pathological point of view, all the tumors had the same features: invasive ductal carcinomas, imprecisely delimited, increased consistency, firm-tough, due to calcifications and to the desmoplastic reaction, tumor cells with cells displayed as cords, tubes, large areas, with destruction of the basal membrane and infiltration into the neighboring tissues. The cells induce an abundant-desmoplastic stroma rich in collagen. The background stroma is densely fibrous and contains foci with periductal and perivascular elastosis. A lymphocyte infiltrate is frequently present. Depending on the tumor size, the following distribution was obtained: $44 \% \mathrm{~T} 1(\varnothing=0-2 \mathrm{~cm}), 46.3 \% \mathrm{~T} 2(\varnothing=2.5-5 \mathrm{~cm})$ and $9.7 \% \mathrm{~T} 3(\varnothing>5 \mathrm{~cm})$.

The patients were aged between 31 and 84 , and figure 1 shows the distribution by age of these patients.

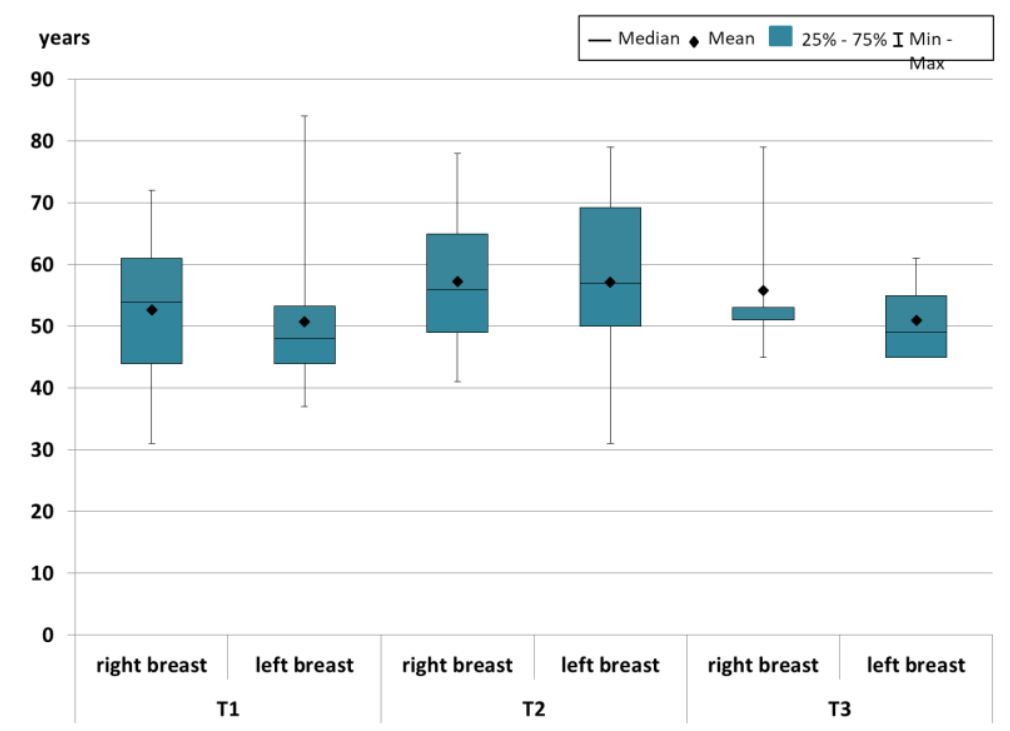

Figure 1. Age of the studied group, according to T1, T2 or $\mathrm{T} 3$ and to the affected breast

In the statistical analysis a significant difference was noticed between the patients' age with T1 and T2 tumor size $(\mathrm{p}<0.05)$, taking into account the whole group. This fact is suggesting that the identification of the tumors is done at an early stage, as a result of the educational programs, and the 
patients pay more attention in having their breast exam. No statistically significant differences ( $\mathrm{p}>$ 0.05 ) were noticed between the age, tumor size and the asymmetry given by the presence of the tumor in the left or right breast (Table 1).

Table 1. Comparative analysis for age values for the studied group and statistical significance

\begin{tabular}{|c|c|c|c|c|c|c|c|c|c|c|c|}
\hline Age & Tumoral dimension & Mean & SE & Median & SD & Min & Max & \multicolumn{4}{|c|}{$p$} \\
\hline \multirow{3}{*}{ Group } & T1 & 51.76 & 1.8044 & 50 & 11.5537 & 31 & 84 & T1-T2 & 0.0343 & \multirow{3}{*}{$\begin{array}{c}\text { T1 } \\
\text { R vs L }\end{array}$} & \multirow{3}{*}{0.5139} \\
\hline & T2 & 57.19 & 1.7626 & 56 & 11.5578 & 31 & 79 & T1-T3 & 0.742 & & \\
\hline & T3 & 53.67 & 3.6056 & 51 & 10.8167 & 45 & 79 & T2-T3 & 0.3297 & & \\
\hline \multirow{3}{*}{ Right breast } & T1 & 52.67 & 2.6244 & 54 & 12.0264 & 31 & 72 & T1-T2 & 0.1843 & \multirow{3}{*}{$\begin{array}{c}\text { T2 } \\
\text { R vs } L\end{array}$} & \multirow{3}{*}{0.9643} \\
\hline & T2 & 57.26 & 2.1617 & 56 & 10.3670 & 41 & 78 & T1-T3 & 0.7896 & & \\
\hline & T3 & 55.80 & 5.9532 & 51 & 13.3116 & 45 & 79 & T2-T3 & 0.6524 & & \\
\hline \multirow{3}{*}{ Left breast } & T1 & 50.80 & 2.5190 & 48 & 11.2652 & 37 & 84 & T1-T2 & 0.9561 & \multirow{3}{*}{$\begin{array}{c}\text { T3 } \\
\text { R vs } L\end{array}$} & \multirow{3}{*}{0.7619} \\
\hline & $\mathbf{T} 2$ & 57.10 & 2.9226 & 57 & 13.0703 & 31 & 79 & T1-T3 & 0.3815 & & \\
\hline & T3 & 51.00 & 3.8297 & 49 & 7.6594 & 45 & 61 & T2-T3 & 0.2452 & & \\
\hline
\end{tabular}

The surgical interventions carried out in all these situations were radical mastectomies performed according to the recommended guides. All the patients received previous medication and standardized anesthesia and were admitted in the intensive care unit after the surgery.

\section{Parameters of oxidative stress}

The patients included in the study, on admission into the hospital, were tested for biochemical oxidative stress parameters. Thus, the intensity of the oxidative attack on the lipids was measured by the extension of the final product of the reaction, malondialdehyde (MDA), and the results (Figure 2) showed different average values depending on the tumor size, namely $5.78 \pm 2.05 \mu \mathrm{mol} / 100 \mathrm{~mL}$ for tumors below $2 \mathrm{~cm}, 5.71 \pm 2.48 \mu \mathrm{mol} / 100 \mathrm{~mL}$ for patients with tumors between $2-5 \mathrm{~cm}$, and $4.45 \pm$ $1.71 \mu \mathrm{mol} / 100 \mathrm{~mL}$ for patients from the T3 category. The recorded values are significantly changed statistically, ( $p, 0.0247)$ suggesting clear differences given by the tumor size. In terms of asymmetry of the tumor presence, in patients belonging to the $\mathrm{T} 1$ category, when the tumor is situated in the right breast, the MDA value, average value, $5.67 \pm 1.7105 \mu \mathrm{mol} / 100 \mathrm{~mL}$, is smaller than in patients with the tumor located in the left breast, $5.89 \pm 2.3905 \mu \mathrm{mol} / 100$. For T2 classification, the obtained values are $5.38 \pm 2.47 \mu \mathrm{mol} / 100$ for tumors of the right breast versus $6.08 \pm 2.45 \mu \mathrm{mol} / 100 \mathrm{~mL}$ for tumors of the left breast. For tumors bigger than $5 \mathrm{~cm}$ located in the right breast, the average MDA value is $4.34 \pm$ $1.47 \mu \mathrm{mol} / 100 \mathrm{~mL}$, respectively $4.59 \pm 0.58 \mu \mathrm{mol} / 100$ - left breast. No statistically significant differences were noticed. 


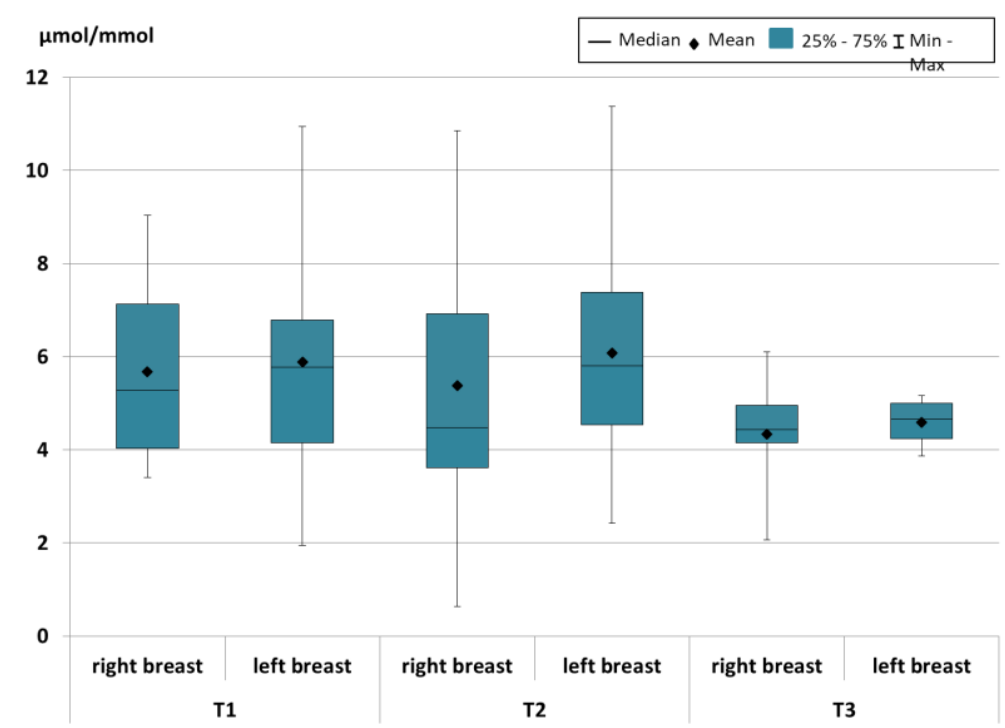

Figure 2. MDA of the studied group, according to T1, T2 or $\mathrm{T} 3$ and to the affected breast

The copper-oxidase activity of ceruloplasmin, for the whole studied group, proved to be higher than the normal average values recorded in the specialized literature (100 U.I., where 1 unit represents $\mu$ moles of protein turning into oxidized form in one minute, in standard conditions). During the statistical analysis of the values of ceruloplasmin (CP) activity, no statistically significant differences were noticed between $\mathrm{CP}$ values in patients with T1 (116.78 $\pm 50.77 \mathrm{UI})$, T2 (121.81 $\pm 42.58 \mathrm{UI})$ or T3 (136.33 \pm 66.14 UI) considering the whole group, or only the patients with tumors of the right breast or those with tumors of the left breast; this data is shown in Figure 3.

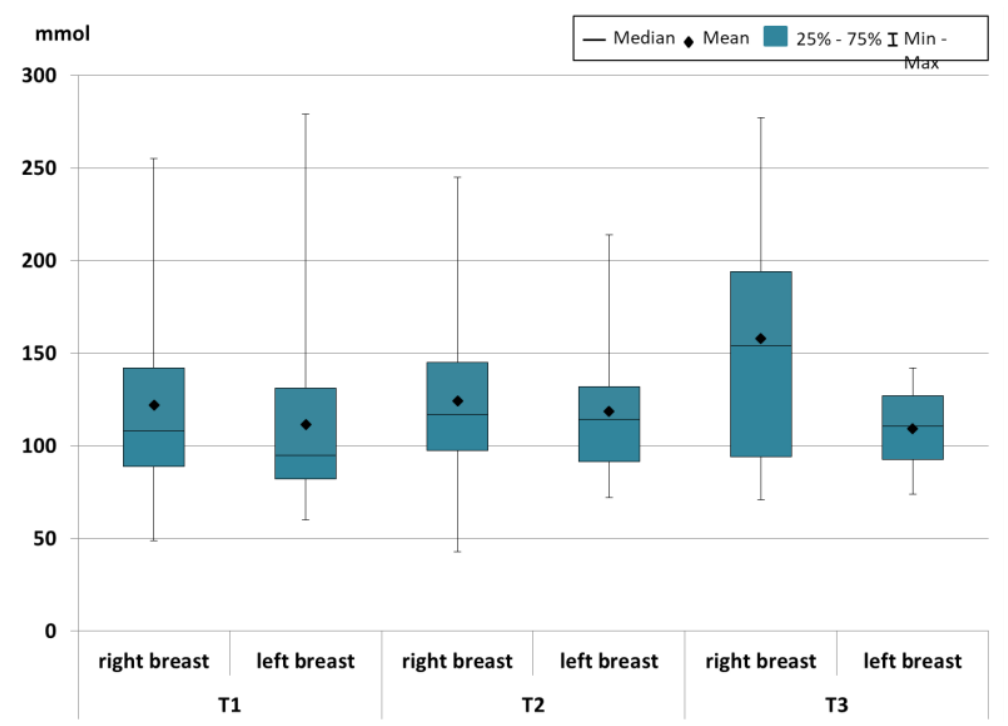

Figure 3. CP of the studied group, according to T1, T2 or $\mathrm{T} 3$ and to the affected breast

In the statistical analysis of the values of the albumin thiols resulting from the oxidative damage caused by the reactive oxygen species on proteins, no statistically significant differences were noticed between the values recorded in the patients with $\mathrm{T} 1(334.80 \pm 137.42 \mathrm{mM}), \mathrm{T} 2(355.30 \pm 124.12 \mathrm{mM})$ or T3 (347.56 $\pm 347.56 \mathrm{mM})$ considering the whole group, or only in patients with tumors of the right breast or in those with tumors of the left breast (Figure 4). 


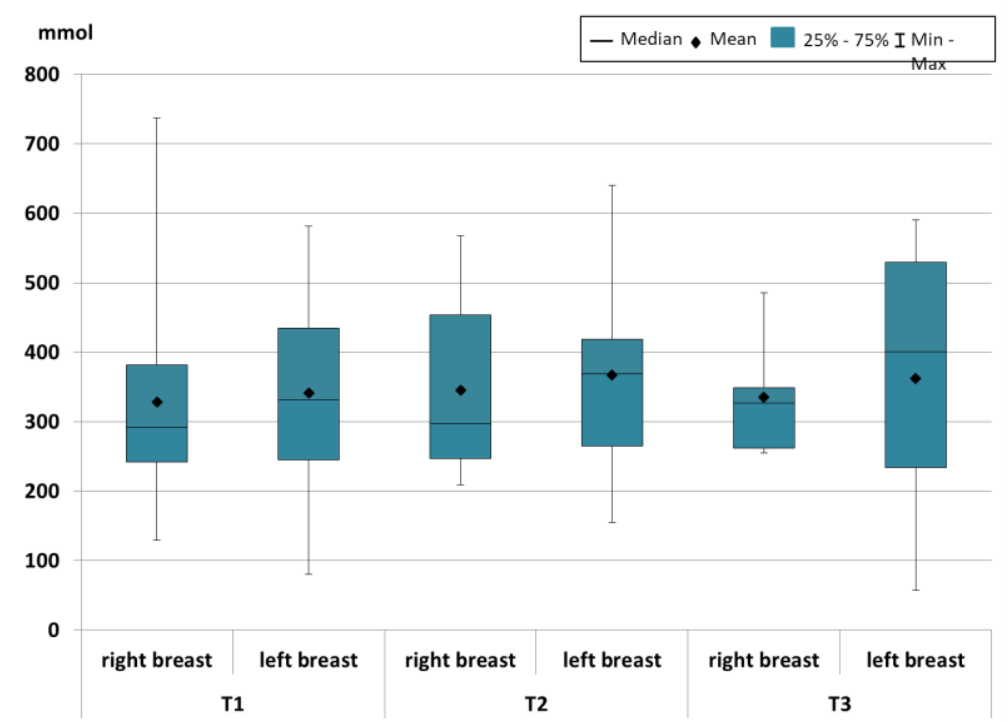

Fig. 4. Determination of albumin thiols in patients (AT) according to $\mathrm{T} 1, \mathrm{~T} 2$ or $\mathrm{T} 3$ and to the affected breast

The balance of oxidative stress in patients with breast cancer is inclined towards producing active species to the detriment of capturing them. These values are generally associated with the clinical status of the patients, with their eating style, with their lifestyle in general. What we are able to say is that the determination of the total antioxidants through the monitoring reaction of the serum ability to reduce iron (FRAS) can complete the picture of the useful markers in monitoring oxygen metabolism and the production of associated reactive species. The achieved results are shown below, and significant statistical differences are noticed $(\mathrm{p}=0.0452)$ depending on the tumor size. The average values are, for T1 and, respectively, T2, $1.30 \pm 0.43 \mu \mathrm{mol} / 1$, and $1.29 \pm 1.21 \mu \mathrm{mol} / \mathrm{l}$ versus $\mathrm{T} 3-1.75 \pm$ $0.69 \mu \mathrm{mol} / \mathrm{l}$ (fig.5).

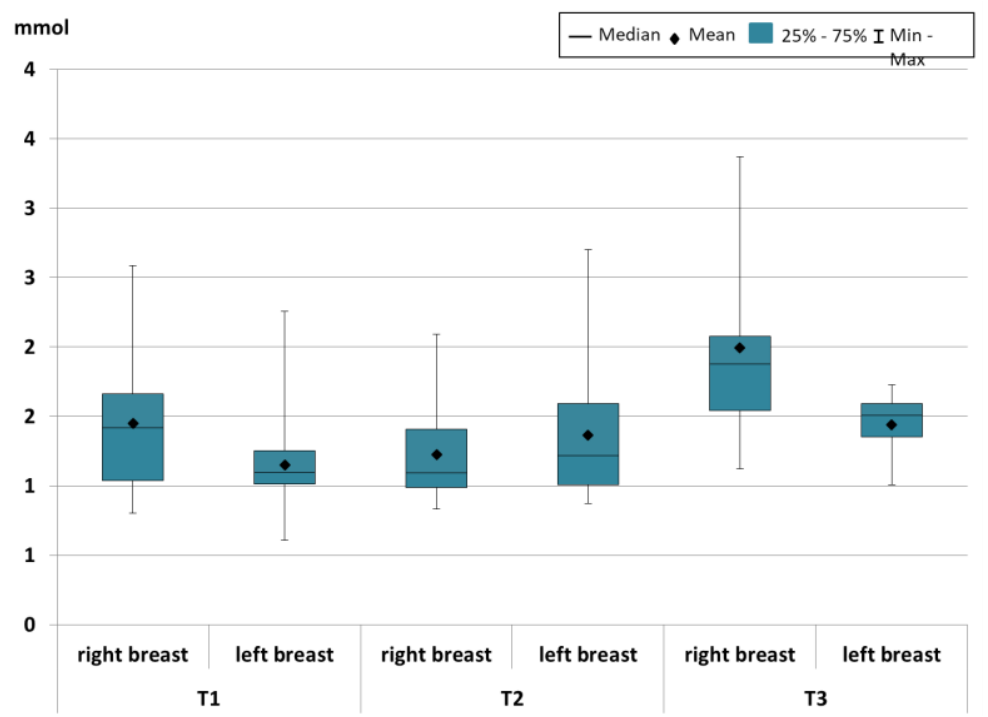

Figure 5. FRAS for the studied group, according

to $\mathrm{T} 1, \mathrm{~T} 2$ or $\mathrm{T} 3$ and to the affected breast

Significant statistical differences were observed in the statistical analysis for the whole group between T1-T3 and T2-T3, for patients with right breast tumor between T2-T3, and for patients with $\mathrm{T} 1$ between those with right and left breast cancer .No statistically significant differences were observed between FRAS values in patients with T1, T2 or T3, considering only patients with tumors in 
the left breast. There were also no differences between FRAS values in patients with right or left breast tumors, neither for T2 nor for T3 (table 2).

Table 2. Comparative analysis for FRAS values in the studied group and statistical significance

\begin{tabular}{|c|c|c|c|c|c|c|c|c|c|c|c|}
\hline FRAS & Tumoral dimension & Mean & SE & Median & SD & Min & Max & \multicolumn{4}{|c|}{$p$} \\
\hline \multirow{3}{*}{ Group } & T1 & 1.30 & 0.0684 & 1.183 & 0.4381 & 0.608 & 2.585 & T1-T2 & 0.8861 & \multirow{3}{*}{$\begin{array}{c}\text { T1 } \\
\text { R vs } L\end{array}$} & \multirow{3}{*}{0.0452} \\
\hline & $\mathbf{T 2}$ & 1.29 & 0.0601 & 1.215 & 0.3939 & 0.834 & 2.701 & T1-T3 & 0.0228 & & \\
\hline & T3 & 1.75 & 0.2315 & 1.547 & 0.6945 & 1.007 & .,37 & T2-T3 & 0.0199 & & \\
\hline \multirow{3}{*}{ Right breast } & T1 & 1.45 & 0.1070 & 1.415 & 0.4902 & 0.805 & 2.585 & T1-T2 & 0.1149 & \multirow{3}{*}{$\begin{array}{c}\text { T2 } \\
\text { R vs } L\end{array}$} & \multirow{3}{*}{0.3681} \\
\hline & T2 & 1.22 & 0.0685 & 1.095 & 0.3284 & 0.834 & 2.094 & T1-T3 & 0.1054 & & \\
\hline & T3 & 2.00 & 0.3796 & 1.875 & 0.8489 & 1.121 &., 37 & T2-T3 & 0.0128 & & \\
\hline \multirow{3}{*}{ Left breast } & T1 & 1.15 & 0.0716 & 1.096 & 0.3203 & 0.608 & 2.256 & T1-T2 & 01417 & \multirow{3}{*}{$\begin{array}{c}\text { T3 } \\
\text { R vs } L\end{array}$} & \multirow{3}{*}{0.2555} \\
\hline & $\mathbf{T 2}$ & 1.37 & 0.1016 & 1.219 & 0.4544 & 0.875 & 2.701 & T1-T3 & 0.0969 & & \\
\hline & T3 & 1.44 & 0.1535 & $1, .085$ & 0.3070 & 1.007 & 1.728 & T2-T3 & 0.53 & & \\
\hline
\end{tabular}

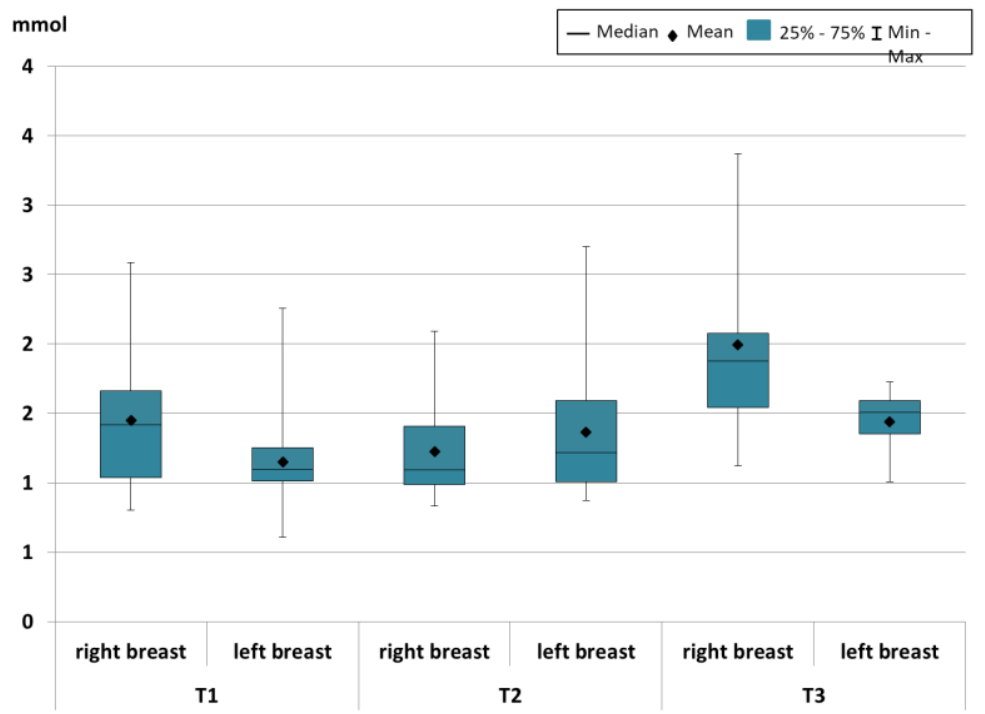

Figure 5. FRAS for the studied group, according to T1, T2 or T3 and to the impaired breast

Further on, the next statistical correlation analysis studies were carried out, initially followed the analysis of stress parameters investigated according to age and tumor size, more precisely the clinical parameters. The results are shown in table 1, and they illustrate a negative, acceptable correlation between age, oxidative protein degradation and small tumor sizes, of less than $2 \mathrm{~cm}(\mathrm{p}=0.008)$. A similar correlation is also recorded for tumors classified in the T2 category, where there is an acceptable positive correlation between CP-FRAS and TA-FRAS ( $p>0.05$ ) as well. In patients with tumors classified in the T3 group, a good negative correlation is recorded between age-MDA ( $p$ > 0.05 ), an acceptable positive relation between age-FRAS ( $p>0.05$ ) and a very good positive correlation between CP-FRAS ( $\mathrm{p}<0.05)$ (Table 3). 
Table 3. Statistical analysis of correlation between the studied indicators for the entire group and the statistical significance

\begin{tabular}{|c|c|c|c|c|c|c|c|c|c|c|}
\hline \multirow{2}{*}{\multicolumn{2}{|c|}{ Indicators }} & \multicolumn{3}{|c|}{ T1 } & \multicolumn{3}{|c|}{$\mathbf{T} 2$} & \multicolumn{3}{|c|}{$\mathbf{T 3}$} \\
\hline & & \multirow{2}{*}{$\begin{array}{c}\text { r / rho } \\
0.1174\end{array}$} & \multirow{2}{*}{$\begin{array}{l}\text { Colton } \\
*\end{array}$} & \multirow{2}{*}{$\frac{p}{0.4646}$} & \multirow{2}{*}{$\begin{array}{c}\text { r / rho } \\
0.0117\end{array}$} & \multirow{2}{*}{$\begin{array}{l}\text { Colton } \\
*\end{array}$} & \multirow{2}{*}{$\frac{p}{0.9405}$} & \multirow{2}{*}{$\frac{\text { r / rho }}{-0.6070}$} & \multirow{2}{*}{$\frac{\text { Colton }}{* * * *}$} & \multirow{2}{*}{$\begin{array}{c}\boldsymbol{P} \\
0.076\end{array}$} \\
\hline \multirow{4}{*}{ Age - } & MDA & & & & & & & & & \\
\hline & $\mathbf{C P}$ & -0.1090 & $*$ & 0.496 & 0.2182 & $*$ & 0.1591 & -0.1453 & $*$ & 0.6777 \\
\hline & TA & -0.4084 & $* *$ & 0.008 & -0.2820 & $* *$ & 0.0671 & -0.0086 & $*$ & 0.9484 \\
\hline & FRAS & -0.1935 & $*$ & 0.2245 & -0.0020 & $*$ & 0.9896 & -0.2907 & $* *$ & 0.4101 \\
\hline \multirow{3}{*}{ MDA - } & $\mathbf{C P}$ & 0.0494 & $*$ & 0.7572 & 0.2267 & $*$ & 0.1433 & 0.0429 & $*$ & 0.9128 \\
\hline & TA & 0.0303 & $*$ & 0.8506 & 0.1728 & $*$ & 0.2665 & -0.0373 & $*$ & 0.924 \\
\hline & FRAS & 0.0760 & $*$ & 0.6351 & 0.0357 & $*$ & 0.8194 & -0.1167 & $*$ & 0.7435 \\
\hline \multirow{2}{*}{ CP - } & TA & 0.0987 & $*$ & 0.5376 & -0.0074 & $*$ & 0.9627 & 0.0315 & $*$ & 0.9359 \\
\hline & FRAS & 0.2284 & $*$ & 0.1503 & 0.2955 & $* *$ & 0.0546 & 0.7833 & $* * * *$ & 0.0172 \\
\hline TA - & FRAS & 0.1639 & $*$ & 0.3046 & 0.2820 & $* *$ & 0.0671 & 0.3167 & $* *$ & 0.4101 \\
\hline
\end{tabular}

In our attempt to identify any possible metabolic changes that occurred following oxygen metabolization in right breast cancer patients, the statistical analysis of correlation of the values registered for the determined oxidative stress parameters show an acceptable positive correlation between age-MDA ( $p>0.05)$ and an acceptable negative correlation between age-TA, age-FRAS and CP-TA ( $p>0.05)$ in patients with small tumors (T1), an acceptable negative correlation between ageMDA ( $>$ > 0.05) and a positive acceptable correlation between MDA-TA and TA-FRAS ( $p<0.05)$ in patients in subgroup T2, and for patients with right breast tumors larger than $2 \mathrm{~cm}$, there is a good negative correlation between age-MDA, age-FRAS ( $p>0.05$ ), a good positive correlation between MDA-SA and CP-FRAS ( $>>0.05)$, and an acceptable negative correlation between age-CP ( $>0.05)$ (table 4).

Table 4. Statistical analysis of correlation between the studied indicators for the patients with right breast tumors and the statistical significance

\begin{tabular}{|c|c|c|c|c|c|c|c|c|c|c|}
\hline \multirow{2}{*}{ Indicators } & \multicolumn{3}{|c}{ T1 } & \multicolumn{3}{c|}{ T2 } & \multicolumn{3}{c|}{ T3 } \\
\cline { 2 - 11 } & r/ rho & Colton & $p$ & r/ rho & Colton & $p$ & r / rho & Colton & $p$ \\
\hline \multirow{3}{*}{ Age - } & MDA & 0.3444 & $* *$ & 0.1254 & -0.3399 & $* *$ & 0.1125 & -0.6669 & $* * *$ & 0.1333 \\
\cline { 2 - 11 } & CP & 0.1827 & $*$ & 0.4252 & 0.1083 & $*$ & 0.6228 & -0.3591 & $* *$ & 0.45 \\
\cline { 2 - 12 } & TA & -0.2793 & $* *$ & 0.2195 & -0.1395 & $*$ & 0.5245 & 0.0513 & $*$ & 0.95 \\
\hline \multirow{3}{*}{ MDA - } & FRAS & -0.2858 & $* *$ & 0.2086 & -0.1187 & $*$ & 0.5886 & -0.6669 & $* * *$ & 0.1333 \\
\cline { 2 - 11 } & TA & -0.0419 & $*$ & 0.8545 & 0.0909 & $*$ & 0.68 & 0.1320 & $*$ & 0.8324 \\
\hline \multirow{2}{*}{ CP - } & FRAS & -0.0851 & $*$ & 0.7114 & 0.2362 & $*$ & 0.2746 & 0.2471 & $*$ & 0.6886 \\
\cline { 2 - 11 } & FRAS & -0.2684 & $* *$ & 0.2377 & 0.1656 & $*$ & 0.4473 & 0.0332 & $*$ & 0.9578 \\
\hline TA - & FRAS & 0.1545 & $*$ & 0.4983 & 0.5012 & $* * *$ & $\mathbf{0 . 0 1 5 8}$ & -0.2253 & $*$ & 0.7156 \\
\hline
\end{tabular}


The data obtained by statistical correlation analysis between the values of the indicators studied in patients with left breast tumors according to the tumor size is shown in table 5, and it reveals the following features: a good negative correlation between age-TA $(p<0.001)$ and age-CP $(p<0.01)$, an acceptable negative correlation between age-FRAS ( $p>0.05$ ), and a positive acceptable correlation between CP-TA $(\mathrm{p}<0.05)$ in small tumors, T1. For T2 tumors, there is an acceptable positive correlation between age-CP ( $\mathrm{p}<0.05)$, age-MDA and CP-FRAS ( $\mathrm{p}>0.05)$, an acceptable negative correlation between age-TA ( $p<0,05)$ and MDA-FRAS ( $p>0.05)$, and, in terms of T3 classification, there is a very good positive correlation between SA-FRAS $(p<0.05)$, a very good negative correlation between MDA-SA ( $p>0,05)$, a good negative correlation between age-MDA and MDA-FRAS ( $p>$ $0.05)$, and a good positive correlation between age-CP ( $>>0.05)$.

Table 5. Statistical analysis of correlation between the studied indicators for the patients with left breast tumors and the statistical significance

\begin{tabular}{|c|c|c|c|c|c|c|c|c|c|c|}
\hline \multirow{2}{*}{\multicolumn{2}{|c|}{ Indicators }} & \multicolumn{3}{|c|}{$\mathbf{T 1}$} & \multicolumn{3}{|c|}{$\mathbf{T} 2$} & \multicolumn{3}{|c|}{ T3 } \\
\hline & & r / rho & Colton & $p$ & r / rho & Colton & $p$ & r / rho & Colton & $P$ \\
\hline \multirow{4}{*}{ Age - } & MDA & -0.0680 & $*$ & 0.7771 & 0.3387 & $* *$ & 0.144 & -0.6408 & $* * *$ & 0.3592 \\
\hline & $\mathbf{C P}$ & -0.5894 & $* * *$ & 0.0072 & 0.4741 & $* *$ & 0.0347 & 0.6556 & $* * *$ & 0.3444 \\
\hline & TA & -0.7376 & $* * *$ & 0.0003 & -0.4544 & $* *$ & 0.0441 & 0.2189 & $*$ & 0.7811 \\
\hline & FRAS & -0.3465 & $* *$ & 0.1338 & 0.0580 & $*$ & 0.8065 & 0.1690 & $*$ & 0.831 \\
\hline \multirow{3}{*}{ MDA - } & $\mathbf{C P}$ & 0.0926 & $*$ & 0.6954 & 0.1701 & $*$ & 0.4733 & -0.2347 & $*$ & 0.7653 \\
\hline & TA & 0.1827 & $*$ & 0.4406 & -0.2204 & $*$ & 0.3504 & -0.8232 & $* * * *$ & 0.1768 \\
\hline & FRAS & 0.2256 & $*$ & 0.3341 & -0.2505 & $* *$ & 0.2842 & -0.6835 & $* * *$ & 0.3165 \\
\hline \multirow{2}{*}{$\mathrm{CP}$ - } & TA & 0.4582 & $* *$ & 0.0435 & -0.1471 & $*$ & 0.5359 & 0.2154 & $*$ & 0.7846 \\
\hline & FRAS & 0.1422 & $*$ & 0.5465 & 0.2602 & $* *$ & 0.264 & 0.3878 & $* *$ & 0.6122 \\
\hline TA - & FRAS & 0.2496 & $*$ & 0.2842 & 0.1068 & $*$ & 0.6488 & 0.9603 & $* * * *$ & 0.0397 \\
\hline
\end{tabular}

Breast cancer is the most common type of neoplasm in women worldwide, accounting for approximately $51.6 \%$ of all cancers, with a mortality rate of $14.6 \%$.

In Romania, breast cancer occupies the $1^{\text {st }}$ place, representing approximately $11.5 \%$ of the total cases of neoplasia, with a percentage of $25.1 \%$ of new cases diagnosed in 2018 , and with a mortality rate of $6.6 \%[17,18]$.

Given the fact that lately the incidence of this type of cancer has been increasing, we may say that this pathology will soon become a matter of national interest.

The patient's prognostic is determined by different clinical and biological factors, such as: age at diagnosis, tumor size, the grading of the tumor differentiation and the expression of certain genes [19].

The occurrence incidence of this malignancy is increasing fast until the age of 50, then it shows a slow growth curve, thus suggesting that the process of carcinogenesis may be influenced by multiple endogenous factors - such as the woman's hormonal status [20].

Investigations of biochemical parameters of oxidative stress were conducted on 93 patients with breast cancer, a group chosen to be as homogeneous as possible, in terms of the tumor type and of the surgical treatment applied, but stratified according to the tumor size, age and symmetry of localization (right breast versus left breast). By this study, we attempted to identify certain differences given by the tumor asymmetry, carrying out a series of statistical calculations for these purposes. For the investigated group, the data showed that there are no statistically significant differences $(p>0.05)$ 
between the patients' age, tumor size and location, referring, at this point, to the asymmetry given by the tumor presence in the left or right breast.

The age of the patients included in the study was between 31 and 84 , and depending on the tumor size, the following distribution was made: $44 \% \mathrm{~T} 1(\varnothing=0-2 \mathrm{~cm}), 46.3 \% \mathrm{~T} 2(\varnothing=2.5-5 \mathrm{~cm})$ and $9.7 \% \mathrm{~T} 3$ $(\varnothing>5 \mathrm{~cm})$.

In our study, the probability of diagnosing neoplasia on the right side is higher, in percentage, than the one on the left side in the group of women aged below 50, and higher on the left side in the group of age over 50. This result is similar to that of other studies, and it may be considered that age is a predictive factor in terms of laterality of mammary neoplasm [21, 22, 23, 24, 25], but it is not yet certain that it is a prognostic factor, like in other studies [27, 28, 29, 30].

A control study on a large number of patients showed that left-handed women had a higher risk than right-handed ones of developing breast cancer in time, without revealing a predictive factor in this regard $[11,31]$.

There have been other studies in the specialized literature, and, for example, Alexey Petrovich [32] made a comparative analysis of neoplasia laterality, taking into account the clinical-morphological parameters. Results have shown that, in percentage, the primary tumor situated in the right breast exceeded the localization on the left side, with major tendencies of metastasis at ganglion level. Nouh et al. [33] proved that the laterality of the breast neoplasm and the metastasis at ganglion level depend on the dominant hemisphere. Our data does not reveal these results, due to the small number of investigated patients.

It is known that oxidative stress can be modulated by both exogenous and endogenous factors.

ROS can appear from numerous intracellular sources - endogenous pathway- and the most important are mitochondria, NADPH oxidases, and other enzymes. Paulo Luiz de Sá Junior, Diana Aparecida Dias Camara, et al [34] and Cristina Cadenas, Dennis Franckestein, et al [35] have demonstrated that levels of oxidative stress metabolites (MDA and other) can be influenced by age and tumor size.

Our study tried to identify the possible biochemical changes caused by oxygen metabolization and the production of oxidative stress depending on the asymmetry of the tumor localization. One of the important factors of carcinogenesis is the alteration of oxidative stress and the release of free radicals. For this purpose, the biochemical parameters of oxidative stress were investigated, namely lipid peroxides, as a measure of oxidative lipid degradation, the activity of ceruloplasmin, an enzyme with a clear and certain oxidative activity, the concentration of total albumin thiols as a marker of oxidative degradation of circulating proteins, and the determination of total antioxidants, by quantifying the ability of serum to reduce iron. As you can see from our study, the value of biochemical parameters is influenced by the tumor size. Thus, the metabolite value is directly proportional to the tumor size.

Fabiola Lilí Sarmiento-Salinas, Alam Delgado-Magallón,et al [36] showed that one of the consequences of mitochondrial disfunction that has been involved in several aspects of carcinogenesis is the production of ROS and elevated ROS levels found in tumor cells. It has also been shown that invasive breast cancer cells have increased oxidative phosphorylation (OXPHOS), mitochondrial biogenesis, and oxygen consumption rates when compared to their non-invasive counterparts [37].

Hormonal factors are relevant in the development of breast tumors. These factors are strongly related to oxidative stress (OS) through the generation of reactive oxygen species (ROS) as Subir Singh, Ramkumar Rajendran, et al [38] demonstrated in their study. They did a comparative study on two groups, namely one group with positive hormonal breast cancer receptors and another with negative hormonal receptors.

Obesity is considered a risk factor in oncogenesis, influenced by various conditions such as physical activity, nutrition and diet. The role of some specific nutrients in cancer etiology has been based on epidemiological studies, supported by biological credibility. Nutrition-mediated oxidative stress plays a crucial role in carcinogenesis. Some of the vital dietary components are associated with oxidative stress like: alcohol, carbohydrates, fatty lipids, vitamins and fibers. 
Alcohol is a carcinogen linked with breast, oropharyngeal, colorectal, liver, and esophageal cancers by producing oxidative stress, which, consequently, causes severe dysfunction and damage to the intra- and extra-cellular network and functions, which ultimately cause chromosomal abnormalities, DNA damage, DNA methylation modification, signaling pathway alteration, and tumor necrosis factor $\alpha(\mathrm{TNF}-\alpha)$ release.

Numerous epidemiological studies supported a positive interaction between breast cancer risk and alcohol [39]. A meta-analysis demonstrated that high alcohol consumption (10 $\mathrm{g}$ of ethanol consumption per day) was highly associated with the presents of $\mathrm{ER}+\mathrm{PR}+, \mathrm{ER}+\mathrm{PR}-, \mathrm{ER}+$, and $\mathrm{ER}-$ breast tumors, but not ER-PR- tumors [40].

Carbohydrate quality could affect breast cancer, by influencing plasma levels of glucose and insulin, and by causing insulin resistance [41]. Many studies described a potential relationship between glycemic index (GI), degree of cancer risk, and intake of carbohydrate quality [42-45].

Dietary lipids or fats are frequently blamed as the key source energy that influences the relative FA configuration of biological membranes defining its sensibility to oxidative changes [46]. Recent scientific studies concluded the association between EFAs and the risk of breast, bladder, colorectal, lung, or prostate cancers [47-49]

The protective action of fibers that is important for our health is not only associated with colorectal cancer, but also with other cancer types. A study showed an $11 \%$ decrease in breast cancer risk appeared at individuals that have consumed a fiber-rich diet [50]. WCRF assessment board concluded an inadequate level of data regarding the relationship between dietary fiber and breast cancer risk.

According to previous studies, vitamin A, B, C, D, and E, have been implicated in the risk of cancer occurrence [161-165]. Vitamins C, D, and E and selenium have antioxidant properties and all protect against oxidative stress and its implication in carcinogenesis. A case-control study involving women from Klang Valley and Selangor, Malaysia, demonstrated that a good antioxidant consumption, including vitamins $\mathrm{A}$ and $\mathrm{E}$, can reduce oxidative stress and breast cancer risk [51].

We recorded correlations between oxidative parameters and age, establishing once more that the production of free radicals is a process characteristic for the tumor presence and its size, without succeeding in answering the dual cause, namely whether oxidative stress is a cause or a consequence of the tumor presence, but its intensity most certainly grows with age.

Oxidative stress can be diminished by antioxidant medication, efficient in elderly patients without oncological pathology. In the case of tumor presents this antioxidant therapy should be performed, monitored according to the oncostatic treatment, ideally before surgery, with great care and caution in chemotherapy dynamics, and only one month after the radiation treatment has finished.

It is true that the identification of the biochemical parameters specific to oxidative stress can be compared depending on the histopathological and immunohistochemical factors. Our study used only a part of histopathological factors, namely the tumor size and invasive breast cancers.

Tumor size is considered a valuable prognostic factor in the etiology of breast neoplasm, thus small lesions are associated with reduced symptomatology and vice versa [52].

The statistical analysis of correlation between the values of the studied indicators showed for the whole group:

- at T1 - an acceptable negative correlation between age-SA $(\mathrm{p}<0.01)$

- at $\mathrm{T} 2$

$\circ \quad$ an acceptable negative correlation between age-SA ( $p>0.05)$

$\circ \quad$ an acceptable positive correlation between CP-FRAS and SA-FRAS ( $p>0.05)$

- at T3

$\circ \quad$ a good negative correlation between age-MDA $(\mathrm{p}>0.05)$

$\circ \quad$ an acceptable positive correlation between age-FRAS $(p>0.05)$ 
○ a very good positive correlation between CP-FRAS $(\mathrm{p}<0.05)$

The statistical correlation analysis between the values of the studied indicators showed for patients with tumors of the right breast:

- at $\mathrm{T} 1$

$\circ \quad$ an acceptable positive correlation between age-MDA ( $\mathrm{p}>0.05)$

$\circ \quad$ an acceptable negative correlation between age-SA, age-FRAS and CP-SA ( $p>0.05)$

- at $\mathrm{T} 2$

$\circ \quad$ an acceptable negative correlation between age-MDA $(\mathrm{p}>0.05)$

$\circ \quad$ an acceptable positive correlation between MDA-SA and SA-FRAS $(\mathrm{p}<0.05)$

- at T3

$\circ \quad$ a good negative correlation between age-MDA, age-FRAS ( $p>0.05)$

$\circ \quad$ a good positive correlation between MDA-SA and CP-FRAS $(\mathrm{p}>0.05)$

$\circ \quad$ an acceptable negative correlation between age-CP ( $\mathrm{p}>0.05)$.

The statistical correlation analysis between the values of the studied indicators showed for patients with tumors of the left breast:

- at T1

$\circ \quad$ a good negative correlation between age-SA $(\mathrm{p}<0.001)$ and age-CP $(\mathrm{p}<0.01)$

$\circ \quad$ an acceptable negative correlation between age-FRAS $(p>0.05)$

$\circ \quad$ an acceptable positive correlation between CP-SA $(\mathrm{p}<0.05)$

- at $\mathrm{T} 2$

$\circ \quad$ an acceptable positive correlation between age-CP $(\mathrm{p}<0.05)$, age-MDA and CP-FRAS ( $>$ $0.05)$

$\circ \quad$ an acceptable negative correlation between age-SA $(\mathrm{p}<0.05)$ and MDA-FRAS $(\mathrm{p}>0.05)$

- at T3

$\circ \quad$ a very good positive correlation between SA-FRAS $(\mathrm{p}<0.05)$

$\circ \quad$ a very good negative correlation between MDA-SA ( $p>0.05)$

$\circ \quad$ a good negative correlation between age-MDA and MDA-FRAS ( $p>0.05)$

$\circ \quad$ a good positive correlation between age-CP $(p>0.05)$.

The above-mentioned results have shown in most cases a positive correlation between age and MDA for patients with small tumors and positive negative correlations for patients with tumors over 2 $\mathrm{cm}$, which shows that oxidative stress may be influenced by the age and size of the tumor, as shown in other works as well [52-54].

Through the conducted investigations, it has been found that there is a very strong correlation between the values of lipid peroxidation determined by measuring malondialdehyde and the values of ceruloplasmin, a strong correlation between the values of the albumin thiols and the value of the total antioxidants, a statistically significant correlation between the values of ceruloplasmin and the value of albumin thiols, between the values of lipid peroxidation and total thiols. There were no statistically significant correlations between the values of malondialdehyde and those of antioxidants.

\section{Conclusions}

The data submitted claims that the balance of oxidative stress is more inclined to favor excess production of free oxygen radicals to the detriment of their capture. That demonstrates the defense mechanisms represented by antioxidants cannot fully compensate the lost. Because the tumor is an inducer of oxidative stress, the in taking of antioxidants may favorably modulate the balance of oxidative stress. All these determinations reinforce the idea that an effective compensatory response of the organism to this imbalance of oxidative stress cannot be made without the aid of exogenous antioxidants.

These studies together with other future studies can play an important role in the elucidation of the mechanisms associated with breast cancer in order to identify new therapeutic targets. 


\section{References}

1. LI D, ZHU Y, TANG Q, LU H, LI H, YANG H., A new G6PD knockdown tumor-cell line with reduced proliferation and increased susceptibility to oxidative stress, Cancer Biotherapy Radiopharm, 2009, 24, p.81-90.

2. GUZY RD, et al., Loss of the SdhB, but Not the SdhA, subunit of complex II triggers reactive oxygen species-dependent hypoxia-inducible factor activation and tumorigenesis, Molecular and Cellular Biology, 2008, 28(2), p.718-731.

3. ADLER, V, YIN, Z, TEW, KD, RONAI, Z., Role of redox potential and reactive oxygen species in stress signaling, Oncogene, 1999, 18, p. 6104-6111.

4. MOLONEY JN, COTTER TG ., ROS signalling in the biology and cancer, Seminares in Cell \&Developmental Biology, 2017,https://doi.org/10.1016/j. semcdb.2017.05.023.

5. FANG J, TAKAHIRO S, HIROSHI M.,Therapeutic strategies by modulating oxygen stress in cancer and inflammation, Advanced Drug Delivery Reviews, 2009, 61, p. 290-302.

6. MICHELS KB, MOHLLAJEE AP, ROSET-BAHMANYAR E, BEEHLER GP, MOYSICH KB, Diet and breast cancer: a review of the prospective observational studies, Cancer, 2007, 109, p.27122749.

7. BOREK C., Dietary antioxidants and human cancer, Integrative Cancer Therapy, 2004, 3(4), p.333341.

8. GATE L, PAUL J, BA GN, TEW KD, TAPIERO H., Oxidative stress induced in pathologies: the role of antioxidants, Biomedicine \& Pharmacotherapy, 1999, 53, p.169-180.

9. KANG DH., Oxidative stress, DNA damage, and breast cancer, AACN Clinical Issues, 2002, 13, p.540-549.

10. KIOKIAS S, GORDON MH., Dietary supplementation with a natural carotenoid mixture decreases oxidative stress, European Journal of Clinical Nutrition, 2003, 57, p.1135-1140.

11. SIGOUNAS G, ANAGNOSTOU A, STEINER M., dl-alpha-tocopherol induces apoptosis in erythroleukemia, prostate, and breast cancer cells, Nutrition and Cancer, 1997, 28, p.30-35.

12. BOSE M., HAO X., JU J., HUSAIN A., PARK S., LAMBERT J.D., YANG C.S., Inhibition of tumorigenesis in ApcMin/+mice by a combination of (-)-epigallocatechin-3-gallate and fish oil, Journal of Agricultural and Food Chemistry, 2007, 55, p.7695-7700.

13. CHIO IIC, TUVESON DA., ROS in cancer: The burning question,Trends in Moleclar Medicine, 2017, 23,p. $411-429$.

14. THOMSON CA, STENDELL-HOLLIS NR, ROCK CL, CUSSLER EC, FLATT SW, PIERCE JP., Plasma and dietary carotenoids are associated with reduced oxidative stress in women previously treated for breast cancer, Cancer Epidemiology, Biomarkers \& Prevention , 2007, 16, p.2008-2015.

15. ROSE RC, BODE AM., Analysis of water-soluble antioxidants by high-pressure liquidchromatography, The Biochemical Journal, 1995, 306 (pt 1), p.101-105.

16. MENENDEZ JA., Fine-tuning the lipogenic/lipolytic balance to optimize the metabolic requirements of cancer cell growth: molecular mechanisms and therapeutic perspectives, Biochimica et Biophysica Acta, 2010, 1801, p.381-391.

17. WHO, GLOBAL HEALTH OBSEVATORY GENEVA, 2018, who.int/gho/datebase/en.

18. FERLAY J, COLOMBET M, SOERJOMATARAN et al., Global and Regional Estimates of the incidence and mortality of 38 cancers, Globocan Lyon.IARC/WHO, 2018.

19. McPHERSON K, STEEL CM, DIXON JM., ABC of breast diseases. Breast cancer-epidemiology, risk factors and genetics, BMJ, 2000, 321(7261), p.624-628.

20. ANDERSON W.F., CHU K.C., CHANG S, SHERMAN M.E.,Comparison of age-specific incidence rate patterns for different histopathologic types of breast carcinoma, Cancer Epidemiology Biomarkers \& Prevention, 2004, 13, p.1128-1135.

21. SENIE RT, ROSEN PP, LESSER ML, SNYDER RE, SCHOTTENFELD D, DUTHIE K., Epidemiology of breast carcinoma II: factors related to the predominance of left-sided disease, Cancer, 1980, 46(7), p.1705-1713. 
22. EKBOM A, ADAMI HO, TRICHOPOULOS D, LAMBE M, HSIEH CC, PONTEN J., Epidemiologic correlates of breast cancer laterality (Sweden), Cancer Causes Control, 1994, 5(6), p.510-516.

23. WEISS HA, DEVESA SS, BRINTON LA., Laterality of breast cancer in the United States, Cancer Causes Control, 1996, 7(5), p.539-543.

24. PERKINS CI, HOTES J, KOHLER BA, HOWE HL., Association between breast cancer laterality and tumor location, United States,1994-1998, Cancer Causes Control, 2004, 15(7), p.637-645.

25. WILTING J, HAGEDORN M., Left-right asymmetry in embryonic development and breast cancer: common molecular determinants ? Current Medical Chemistry, 2011, 18, p. 5519-5523.

26. MELNIK Y, SLATER PE, STEINITZ R, DAVIES AM., Breast cancer in Israel: laterality and survival, Journal of Cancer Research and Clinical Oncology, 1979, 95(3), p.291-293.

27. FATIMA N., ZAMAN M.U., MAQBOOL A., KHAN S.H., RIAZ N., Lower incidence but more aggressive behavior of right sided breast cancer in Pakistan women. Does right deserve more respect?, Asian Pacific Journal of Cancer Prevention, 2013, 14(1), p.43-45.

28. ROYCHOUDHURI R., PUTCHA V., MOLLER H., Cancer and laterality: a study of the five major paired organs (UK), Cancer Causes Control, 2006, 17, p.655-662.

29. SUGHRUE T., BRODY JP., Breast tumor laterality in the United States depends upon the country of birth, but not race, PLoS One, 2014 Aug;9(8),e103313.

30. EARNEST C.P., WOOD K.A., CHURCH T.S., Complex multivitamin supplementation improves homocysteine and resistance to LDL-C oxidation, Journal of American College of Nutrition , 2003, 22, p.400-407.

31. DMITRENKO AP., Lateral differences in Ki-67 in breast cancer, Molecular and Clinical Oncology, 2016, Jun;4(6), p.1041-1044.

32. NOUH M.A., ISMAIL H., EL-DIN N.H., ELBOLKAINY M.N., Lymph node metastasis in breast carcinoma: Clinicopathologic correlations in 3747 patients, Journal of the Egyptian National Cancer Institute, 2004, 16, p. 5056.

33. SAED G.M., DIAMOND M.P., FLETCHER N., Updates of the role of oxidative stress in the pathogenesis of ovarian cancer, Gynecologic Oncology, 2017, 145(3), p.595-602.

34. PAULO LUIZ de SA JUNIOR, CAMARA D,et al, The Roles of ROS in Cancer Heterogeneity and Therapy, Oxidative Medicine and Cellular Longevity, 2017, 2017:2467940

35. CADENAS C., FRANCKENSTEIN D., SCHMIDT M., et al, Role of thioredoxin reductase 1 and thioredoxin interacting protein in prognosis of breast cancer. Breast Cancer Research, 2010, https://doi.org/10.1186/bcr2599

36. SARMIENTO-SALINAS FL, DELGADO-MAGALLON A, et al, Breast Cancer Subtypes Present a Differential Production of Reactive Oxygen Species (ROS) and Susceptibility to Antioxidant Treatment, Frontiers in Oncology, 2019, 9:480. doi: 10.3389/fonc.2019.00480

37. KALININA E.V., BEREZOV T.T., SHTIL A.A., et al., Expression of peroxiredoxin 1, 2, 3, and 6 genes in cancer cells during drug resistance formation, Bulletin of Experimental Biology and Medicine, 2012, 153(6), p.878-881

38. SINGH S, RAJENDRAN R, KURODA K, et al, Oxidative stress and breast cancer biomarkers: the case of the cytochrome P450 2E1, Journal of Cancer Metastasis and Treatment, 2016 ,2 , p. 268-276.

39. BROOKS P.J., ZAKHARI S, Moderate alcohol consumption and breast cancer in women: From epidemiology to mechanisms and interventions. Alcohol, Clinical and Experimental Research, 2013, 37, p. 23-30.

40. SUZUKI R., ORSINI N., MIGNONE L., SAJI S., WOLK A, Alcohol intake and risk of breast cancer defined by estrogen and progesterone receptor status-A meta-analysis of epidemiological studies, International Journal of Cancer, 2008, 122, p. 1832-1841.

41. MICHELS K.B., MOHLLAJEE A.P., et al, Diet and breast cancer: A review of the prospective observational studies, Cancer ,2007, 109, p. 2712-2749 
42. TURATI F., GALEONE C., GANDINI S., AUGUSTIN L.S.,et al, High glycemic index and glycemic load are associated with moderately increased cancer risk, Molecular Nutrition \& Food Research, 2015, 59, p.1384-1394.

43. CHOI Y.; GIOVANNUCCI E.; LEE J.E, Glycaemic index and glycaemic load in relation to risk of diabetes-related cancers: A meta-analysis, British Journal of Nutrition ,2012, 108, p. 1934-1947. 44. YE Y., WU Y., XU J., DING K., SHAN X., XIA D, Association between dietary carbohydrate intake, glycemic index and glycemic load, and risk of gastric cancer, European Journal of Nutrition, 2017, 56, p. $1169-1177$.

45. MELKONIANS.C., DANIEL C.R., YE Y., PIERZYNSKI J.A., ROTH J.A, WU X, Glycemic index, glycemic load, and lung cancer risk in non-hispanic whites, Cancer Epidemiology, Biomarkers \& Prevention, 2016, 25, p. 532-539.

46. VARELA-LOPEZ A., QUILES J.L., CORDERO M., et al, Oxidative stress and dietary fat type in relation to periodontal disease, Antioxidants, 2015, 4, p. 322-344.

47. MacLEAN C.H., NEWBERRY S.J., MOJICA W.A., KHANNA P., ISSA A.M., et al, Effects of omega-3fatty acids on cancer risk-A systematic review. JAMA J.Am. Med. Assoc, 2006, 295, p. 403-415.

48. CHAN J.M., GANN P.H., GIOVANNUCCI E.L, Role of diet in prostate cancer development and progression, Journal of Clinical Oncology, 2005, 23, p.8152-8160.

49. ESER P.O., VANDEN HEUVEL J.P., ARAUJO J., THOMPSON J.T, Marine-and plant-derived Omega-3 fatty acids differentially regulate prostate cancer cell proliferation. Molecular and Clinical Oncology, 2013, 1, p. 444-452.

50. DONG J.Y., HE K., WANG P.Y, QIN L.Q, Dietary fiber intake and risk of breast cancer: A metaanalysis of prospective cohort studies, The American Journal of Clinical Nutrition, 2011, 94, p. 900905.

51. SHARHAR S., NORMAH H., FATIMAH A., FADILAH R.N., ROHI G.A., et al, Antioxidant intake and status, and oxidative stress in relation to breast cancer risk: A case-control study, Asian Pacific Journal of Cancer Prevention, 2008, 9, p.343-349

52. PAGE D.L., Adenoid cystic carcinoma of breast, a special histopathologic type with excellent prognosis, Breast Cancer Research and Treatment, 2005, 93, p.189-190.

53. KUMARAGURUPARAN R., NAGHINI S., et al., Tissue lipid peroxidation and antioxidant status in patients with adenocarcinoma of the breast, Clinica Chimica Acta, 2002, 325, p.165-170.

54. KUMARAGURUPARAN R., KABALIMOORTHY J., NAGHINI S., Correlation of tissue lipid peroxidation and antioxidants with clinical stage and menopausal status in patients with adenocarcinoma of the breast, Clinical Biochemistry, 2005, 38, p.154-158. 